\section{PrP and the scrapie agent}

\section{Bruce Chesebro}

WHAT is the relationship between the protein designated PrP (ref. 1) and the as yet uncharacterized infectious agents responsible for transmissible spongiform encephalopathies $^{2}$ such as scrapie? No one yet knows, but two reports in this issue point to ways in which the question may possibly be resolved.

$\mathrm{Xi}$ et al. (page $598^{3}$ ) show that the antibiotic amphotericin B can retard both the clinical symptoms and the appearance of protease-resistant PrP $\left(\mathrm{PrP}^{\mathrm{Sc}}\right)$ aggregates in diseased brain tissue without affecting the levels of agent replication; this finding implies that $\operatorname{PrP}^{\mathrm{Sc}}$ is not the infectious agent itself. Büeler et al. (page $577^{4}$ ) report that mice engineered to lack the gene for PrP show no detectable abnormalities in behaviour or development up to at least seven months of age. These results open the possibility of testing the involvement of PrP in both disease pathogenesis and agent replication in vivo.

\section{Properties}

The high resistance to inactivation of scrapie infectivity by chemicals or Xirradiation has led to suggestions that the agent might possess unique biophysical properties, and perhaps not even have a conventional nucleic acid genome ${ }^{5}$. Others favour the possibility that the transmissible agent is a conventional virus $^{6}$ or an unusual combination of nucleic acid and protein ${ }^{7,8}$. Scrapieassociated $\mathrm{PrP}^{\mathrm{Sc}}$, a macromolecular proteinase $\mathrm{K}$-resistant protein aggregate derived from endogenous $\operatorname{PrP}^{\mathrm{C}}$, co-purifies with scrapie infectivity, which has given rise to debate over the possibility that $\mathrm{PrP}^{\mathrm{Sc}}$ might itself be the transmissible agent. $\operatorname{PrP}^{\mathrm{Sc}}$ is so far distinguished from $\mathrm{PrP}^{\mathrm{C}}$ by its larger size and its relative resistance to digestion by proteinase $\mathrm{K}$. Biosynthetic studies in vitro indicate that normal $\operatorname{Pr} \mathrm{P}^{\mathrm{C}}$, which is expressed on the surface of many cell types, is the precursor of $\mathrm{PrP}^{\mathrm{Sc}}$. The conversion to $\mathrm{PrP}^{\mathrm{Sc}}$ probably occurs at the plasma membrane or along the endocytic pathway to the lysosome ${ }^{9}$. Once formed, $\mathrm{PrP}^{\mathrm{Sc}}$ persists in cells, and its accumulation appears to be responsible for the cell damage sbserved in brain tissue.

$\mathrm{Xi}$ et al. hypothesize that amphotericin B interferes with a component of the infectious agent responsible for the conversion from $\mathrm{PrP}^{\mathrm{C}}$ to $\mathrm{PrP}^{\mathrm{Sc}}$. Surprisingly, retardation of $\mathrm{PrP}^{\mathrm{Sc}}$ accumulation had no apparent effect on the titre of the infectious agent detectable in the same brain samples, meaning that $\operatorname{PrP}^{\mathrm{Sc}}$ itself may not be the transmissible agent responsible for scrapie. One weakness of these data is the difficulty in quantifying both the $\operatorname{PrP}^{\mathrm{Sc}}$ and the titre of the infectious agent in brain samples. This criticism has also been applied to experiments, promoting the opposite viewpoint, which showed a correlation between the inactivation of scrapie infectivity and the destruction of $\operatorname{PrP}^{\mathrm{Sc}}$ during proteolysis in vitro ${ }^{1,10}$.

$\mathrm{Xi}$ et al. also found that amphotericin $B$ was effective only in hamsters infected with the $263 \mathrm{~K}$ strain of scrapie. No effect was observed in mice or hamsters infected with two other scrapie strains. The reason for this strain-specific difference is unclear, but it might be explained if these strains could replicate in different types of brain cell. The results point to the desirability of studying different scrapie strains in attempting to understand the nature of these agents and their pathogenic mechanisms.

Several studies with transgenic mice have indicated that PrP plays a leading part in susceptibility to scrapie. Unlike normal mice, transgenic mice expressing hamster PrP are highly susceptible to hamster-adapted scrapie strains ${ }^{11}$. Paradoxically, in other experiments, mice expressing a foreign mouse PrP genotype, which is usually associated with slower progression to disease, developed disease more rapidly ${ }^{12}$; in this case, the level and location of PrP expression may have been more important than the $\operatorname{PrP}$ genotype in influencing the tempo of disease.

Lastly, transgenic mice expressing a PrP gene with a specific mutation found in some cases of a familial human spongiform encephalopathy (GerstmannSträussler-Scheinker syndrome) developed a degenerative brain disease ${ }^{13}$. These results might suggest that the mutation of PrP created a transmissible scrapie agent de novo. Alternatively, it could be that the PrP mutation increased the susceptibility of these mice to an unknown but ubiquitous 'conventional' virus. However, this disease differed from scrapie and all other related transmissible spongiform encephalopathies in that no protease-resistant $\mathrm{PrP}^{\mathrm{Sc}}$ was detectable in the brains of afflicted mice. Furthermore, the disease does not seem to be easily transmissible. So it seems most likely that this model is not identical to scrapie, but is a manifestation of a metabolic disease due to expression of a mutant protein.

Although all of these transgenic mice models provide evidence that $\operatorname{PrP}$ is a susceptibility factor for the development of scrapie, none of them gives any evidence as to the nature of the agent itself.
Therein lies the importance of the report by Büeler et al. ${ }^{4}$ - their development of a viable normal mouse strain without a functional $\operatorname{PrP}$ gene may provide a unique opportunity to examine the involvement of PrP in replication of the scrapie agent. Tests of the susceptibility of these mice to inoculation with the agent are probably already in progress, and they should produce interesting results no matter what their outcome.

\section{Possibilities}

One can envisage at least three possibilities. First, there might be no clinical disease and no agent replication. This would show that $\operatorname{PrP}$ is required for both processes, and would suggest that PrP might either be a component of the agent itself or a receptor or other type of factor required for the agent to grow successfully in cells. Second, there might be successful agent replication but no apparent disease. This would support the current evidence that accumulation of aggregated $\mathrm{PrP}^{\mathrm{Sc}}$ may cause destruction of brain tissue in a manner similar to other amyloidoses, but would imply that $\mathrm{PrP}^{\mathrm{Sc}}$ is not an essential component of the transmissible agent. Third, there might be both disease and agent replication. This outcome seems unlikely in view of the evidence indicating a central role for PrP. However, Büeler et al. suggest that $\operatorname{Pr} \mathrm{P}$ function in normal mice might be redundant and replaceable by another protein in PrP-negative mice; perhaps the role of PrP in susceptibility to scrapie might also be assumed by another protein.

Taken together, the issues surrounding the spongiform encephalopathies remain complicated, perplexing and (not least) controversial. But we should soon have some interesting data to help address the various questions that need answers.

Bruce Chesebro is in the Laboratory of Persistent Viral Diseases, Rocky Mountain Laboratories, NIH National Institute of Allergy and Infectious Diseases, Hamilton, Montana 59840, USA.

1. McKinley, M. P., Bolton, D. C. \& Prusiner, S. B. Cell 35 57-62 (1983).

2. Chesebro, B. in Virology Vol. 2 (eds Fields, B. N. \& Knipe, D. M.) 2325-2336 (Raven, New York, 1990)

3. Xi, Y. G., Ingrosso, L., Ladogana, A., Masulto, C. \& Pocchiari, M. Nature 356, $598-600$ (1992).

4. Büeler, H. et at. Nature 356, 577-582 (1992)

5. Griffith, J. S. Nature 215, 1043-1044 (1967)

6. Rohwer, R. G. in Current Topics in Microbiology and Immunology Vol. 172 (ed. Chesebro, B. W.) 195-232 (Springer, Berlin--Heidelberg, 1991)

7. Dickinson, A. G. \& Outram, G. W. in Novel infectious Agents and the Central Nervous System, Ciba Fdn Symp. 135 (eds Bock, G. \& Marsh, J.) 63-83 (Wiley, Chichester, 1988)

8. Weissmann, C. Nature 352, 679-683 (1991)

9. Caughey, B. \& Raymond, G. J. J. biol. Chem. 266 18217-18223 (1991)

10. Neary, K., Caughey, B., Ernst, D., Race, R. E. \& Chesebro, B. J. Virol. 65, 1031-1034 (1991)

11. Scott, M. et al. Cell 59, $847-857$ (1989).

12. Westaway, D. et al. Neuron 7, 59-68 (1991).

13. Hsiao, K. et al. Science 250, 1587-1590 (1990) 